\title{
Lean Six Sigma in Africa: Fad or real solution of competitiveness?
}

\author{
Said El Mezouari ${ }^{1}$, Zahira Bouaouda ${ }^{2}$, Hicham Drissi ${ }^{3}$
}

Univ Hassan 1; Laboratory of research in Finance, Accounting and Audit; 26000 Settat; Morocco

1elmezouari_s@yahoo.fr

2bouaoudazahira@yahoo.fr

${ }^{3}$ drissihicham8@gmail.com

\section{ABSTRACT}

Companies tend increasingly to turn to the so-called continuous improvement in order to improve their performance and thus enhance their competitiveness approaches. In times of crisis, the use of these approaches becomes mandatory. In this context, the Lean Six Sigma is incontestably today a vehicle for business development as it allows performance improvement through various appropriate tools on one side, and incitement to contribution of different actors in the company, on the other side.

In Africa, the Lean Six Sigma looks like an opportunity that seems to come at the right time in an environment that seems to need it. Is it then a management instrument emerging from a fad phenomena, or is it a real tool for performance improving for African companies, responding to a real need?

\section{Indexing terms/Keywords}

Lean Management, Lean Six Sigma,African companies, Sustainable Development.

\section{Academic Discipline And Sub-Disciplines}

Management science;

\section{SUBJECT CLASSIFICATION}

Improvement methodologies;

\section{TYPE (METHOD/APPROACH)}

Provide examples of relevant research types, methods, and approaches for this field: E.g., Historical Inquiry; QuasiExperimental; Literary Analysis; Survey/Interview

\section{Council for Innovative Research}

Peer Review Research Publishing System

\section{Journal: International Journal of Management \& Information Technology}

\author{
Vol. 6, No. 3 \\ editor@cirworld.com \\ www.cirworld.com, member.cirworld.com
}




\section{INTRODUCTION}

Lean Six Sigma is a set of statistical tools organized around a rigorous project management. This innovative technique is very popular in North America, combines the best principles of project management with the power of statistical tools and methods. The rigor of this pairing brings surprising results with considerable effort

In a context of globalization and fierce competition among companies, improving productivity, in particular through Lean Six Sigma is no longer a matter of choice. It is an obligation if a company wishes to be present on the international market.

Several success stories have been shared by world-class companies that integrated this knowledge in their management toolbox. It is time for African firms to get started.

Today more than ever, African companies are facing increased competition in local, national, regional and international markets.

Economies globalization with more open markets and its corollaries of borders dismantling, the phenomena of privatization are all factors that argue for upgrading management practices in African companies to meet the challenge of productivity and competitiveness.

However, the deployment of management tools and instruments must be subject to a contextualization exercise. According to N. Sargeane "1"A good practice is an approach that brings value in a given context, which is not necessarily true in a different environment." Thus, if Lean 6 Sigma is considered as good practice that is proven in the North American, Asian and European context, would it bring the same contribution to African companies? It's the answer to this question that will allow us to assess whether this tool is a real solution to competitiveness for African companies.

Indeed, companies can use management tools that have been proven to work in other companies to address internal problems or improve their performance. On the other hand, because each organization is unique, and because of the variety of factors ${ }^{2}$ affecting this organization, the adoption of management instruments must be proceeded by an analysis of the ability of the organization to properly integrate these instruments.

\section{LEAN SIX SIGMA AS A MANAGEMENT INSTRUMENT}

Lean Six Sigma is an approach that combines the "lean", a production system aiming to eliminate the seven forms of wastes: transportation, inventory, motion, waiting, overproduction, over-processing, and defects, in order to reduce the cycle time of a process, and the "Six Sigma" which is a method that aims at reducing the variability in a process output. Lean Six Sigma applies to all organizations, as it is based on a process approach. Its tools are therefore suitable for transactional processes as well.

According to the experience feedback of companies that have implemented Lean Six Sigma, it can turn into deep and lasting business.

Lean Six Sigma is none other than the marriage of two methods for improving processes known and recognized for their effectiveness. Lean was developed within Toyota's factories in the 70s to improve the timeliness, introducing the JIT and reduce costs. Six Sigma is based on an approach based on both the voice of the customer (surveys, etc..) and measurable and reliable data (indicators). It reduces the variability in the production process and improves overall product quality and service. As both methods are customer oriented, when implemented together properly, they reap the benefits of faster processes with lower cost and higher quality.

Quality deficiencies from a customer point of view, as well as delays penalizing a process are the main sources of opportunities identified to improve quality, production costs and profit margin. Based on this assumption, Lean Six Sigma can then be considered as an essential step to improve customer service, ( ) as well as overall profitability.

Table 1 - Additional contributions of Lean and Six Sigma ${ }^{3}$.

\begin{tabular}{|l|l|}
\hline \multicolumn{1}{|c|}{ Lean } & \multicolumn{1}{c|}{ Six Sigma } \\
\hline Main Objectives & Main Objectives \\
- Eliminate wastes & - Reduce variation; \\
- Speed and less resources & - Quality; \\
- Intuitive approach, simple & - Analytical and rational approach, \\
Used tools & complex problems resolving \\
- Value Stream Mapping, 5S; & Used tools \\
- Added Value Analysis & - Voice of Customer (VOC); \\
- Just in Time & - Toolstics; \\
\hline
\end{tabular}

\footnotetext{
${ }^{1}$ Facilitator of the USI Casablanca, edition of July 2010

${ }^{2}$ Theory of contingency factors by Henry Mintzberg

3 «Déployer et Exploiter Lean Six Sigma »Nicolas Volck, éditions d'Organisation, 2009,
} 


\begin{tabular}{|l|l|}
\hline Kaizen & $\bullet$ Control cards; \\
Results & Results \\
- Visible results in short term, by & - Relatively quick wins; \\
$\begin{array}{l}\text { small steps, toward the } \\
\text { sustainability; }\end{array}$ & - Results in middle and long terms \\
\end{tabular}

Transactional processes in the service industries are (in any case in outline?), slightly different from manufacturing industries processes. Lean Six Sigma tools apply to back-office operations just as well as industrial manufacturing operations. It follows the same principles, steps and recommendations.

Equally, dependent on the voice of the customer, third sector organizations, whether business services such as financial institution, banks or insurance companies, or administrative departments of industrial companies and governments, are subject to the same requirements of quality, time and cost.

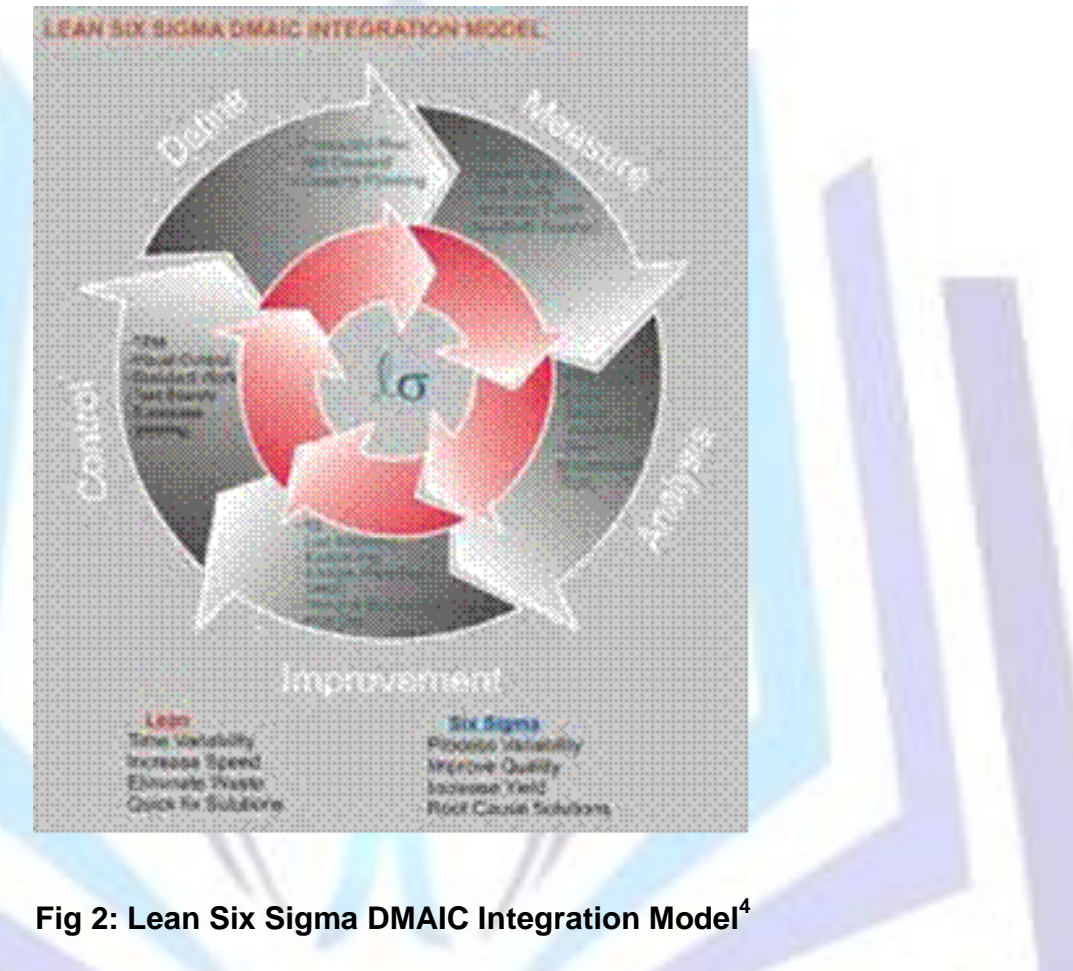

In general, Lean Six Sigma is a participatory approach that involves all stakeholders in the process. Strategic thinking, defects sources identification and solutions generation are always made in collaboration with the operational teams.

Once the areas for improvement are identified, impacts are analyzed, to allow resources allocation to actions that have the greatest influence on key performance indicators.

\section{LEAN SIX SIGMA IN AFRICA}

The implementation of new management instruments was often reserved for companies of a certain size that meets certain organizational criteria. Nevertheless, the African economic sector [1] is characterized by the dominance of the informal sector that represents a large majority of the non-agricultural labor force, employment creation and more than half of the national wealth5. Consequently, to talk about Lean Six Sigma in Africa, leads in fact to observe this practice in a very limited segment of the African economic entities, namely: some public administrations in addition to subsidiaries of multinationals.

On the other hand, the adoption of Lean Six Sigma as a tool of management in African companies is part of the logic of a massive influence of shareholders on these companies. , In fact, the concept's wide-spread notoriety, and the continuing

${ }^{4}$ http://blogpool4tool.com/2013/03/05/lean-six-sigma-tips-for-procurement-and-purchasing-pros/

${ }^{5}$ «Transition démographique et emploi en Afrique subsaharienne : comment remettre l'emploi au cœur des politiques de développement », Raphaël BEAUJEU, Michael KOLIE, Jean-François SEMPERE, Christine UHDER, collection « A SAVOIR 05 », April 2011 
consulting firms publicizing of the methodology, are all factors that have contributed to the craze by the shareholders of African firms to implement this type of management tools in order to allow them more control over companies legally owned by them. This is even more true in the case of African subsidiaries of multinational companies, where the geographical distance makes direct control over the performance of subsidiaries from global headquarters a challenge.

\subsection{African experiences: case of the Banking Sector}

Banking sector in African countries today is facing more than ever the challenge (of banking?) by encouraging the emergence of entrepreneurship through microfinance and SME financing. This project of banking has prompted many local banks to revolutionize their business through the adoption of so-called progress steps cultures.

According to Ineum Consulting firm ${ }^{6}$, BIAT, a Tunisian private bank and the Libyan subsidiary of PNB Paribas, the Moroccan Bank for Trade and Industry, the Credit Immobilier et Hotelier (Morocco) and the Post Office in Morocco, all led projects within the logic of accelerating quality, reducing agencies' workload and operations cost, based on the methodology of Lean Six Sigma.

According to experts leading these projects, the initial results demonstrated that a "Lean" process ensures a customer satisfaction which becomes in itself a source of motivation for staff and a competitive edge for the company.

Similarly, Standard Bank Group, one of the largest financial institutions in South Africa, published a case study ${ }^{7}$ of the implementation of Lean Six Sigma in its institution.

In the case study presented by "European independent IT research and analysis firm Bloor", Research and Analysis shows that the bank has saved 438 million rand - the equivalent of $\$ 64.8$ million - on a period of four years through its Lean Six Sigma project, "iSixSigma reports".

Standard Bank implemented a process improvement program in its Personal and Business Banking division which provides financial services to individual customers and small and medium enterprises. In 2005, the managers had noticed that the division encountered several problems of operational inefficiencies, including product focused structure that revealed a silo of individual operations for each product group, which drives redundant functions and documents, high error rates, rework and waste

The division had no performance measurement system in place, making it difficult to locate the root causes of the problems facing it and impeded any attempt to find a solution. On that year, the bank has deployed Lean Six Sigma, and focused on projects that address the reduction of waste and process redesign. Following these gains, the Bank has developed a "scorecard" to track improvement results.

\subsection{African experiences: case of the Industrial Sector}

In South Africa, the company Hulamin, an important African operator in the industry of manufacturing aluminum products, launched Lean Six Sigma program, and confirms achieving a gain ${ }^{8}$ of 50 million Rands thanks to its strategy of continuous improvement.

In the same context, "Element Six", a subsidiary of South African group "DeBeers", and global leader in the development and production of technical solutions based on diamond implemented Lean Six Sigma within the framework of programs to improve the workplace, whereby it made significant savings and won an Award of Excellence

\subsection{African experiences: case of the Aeronautical Sector}

The aviation industry has boomed in the African continent, especially in North Africa. The growth of this industry in Africa has been a key driver of the economic development of the continent.

In Morocco, the aviation industry has made its first steps through alliances between European aerospace industries, and European and American aircraft manufacturers. Lean Six Sigma is highly developed in the aviation industry globally, and because of their membership in the global aerospace groups, Moroccan companies have experienced early practices of Lean Six Sigma. Beyond a simple fad, these subsidiaries have been involved in programs deployment of Lean Six Sigma defined by their groups, as part of an effort to improve performance and profitability, as the main reason of being of these subsidiaries is low cost. Indeed, the deployment of Lean Six Sigma is a tool for mastering by the parent companies, subsidiaries, and their performance.

\footnotetext{
${ }^{6}$ Newsletter « Les Afriques »- $\mathrm{N}^{\circ} 83-9$ to 15 July 2009

${ }^{7}$ Source : http://www.guidonps.com/industry-news/south-african-financial-institution-reduces-waste-and-errors-withlean-six-sigma

${ }^{8}$ According to the magazine « HR Future »
} 
Similarly, in Tunisia, the development of the aerospace industry started with the establishment of subsidiaries of foreign groups, which was accompanied by the implementation of improvement initiatives such as Lean Six Sigma.

In South Africa, the implementation of Lean in aircraft maintenance ${ }^{9}$ companies was a failed attempt. This was mostly due to a lack of understanding of the methodology by the stakeholders, and a lack of clear implementation strategy. Overall, the results achieved by the various African organizations in improving their performance, show that the Lean Six Sigma beyond the buzz is perceived today by African organizations as a real improvement tool that can assist them in their quest for performance excellence.

This growth experienced by the Lean Six Sigma has been strongly supported by the presence in Africa of international consulting organizations, specialized in the field, but also through the establishment of training organizations providing specific programs to assist African companies in their Lean Six Sigma journey and developing local skills. The launch in Casablanca of a branch of the University Lean 6 Sigma in order to promote Lean Six Sigma certification and expertise in Morocco is a great example.

Similarly, Morocco's desire to promote the Lean Six Sigma took shape in 2011 in the "INMAA" project, which is led by the Moroccan Ministry of Industry, trade and new technologies in partnership with the National Agency for the Promotion of Small and Medium Enterprises (ANPME), OCP, three Moroccan banks and McKinsey firm.

The "INMAA" project aims to support the Moroccan SMEs, at a rate of 100 companies per year, to improve their competitiveness and their operational excellence through the implementation of "lean management" and through hands-on training for field staff.

If the implementation of the Lean Six Sigma approach in African structures is crowned by a remarkable success in some areas, these experiences corroborate the conclusions of Christophe Bourgeois' study on the impact of difficulties in the adoption by organizations of new management tools.

\subsection{Lean Six Sigma in Africa: what constraints for implementation?}

If Lean Six Sigma seeks standardization as a means of quality, it could be blamed for excess of standardization that could impoverish the creativity in possible responses to a given problem and adaptation to specific needs, resulting in a need to adapt the Lean Six Sigma to cultures and contexts.

In the area of Lean Six Sigma, the majority of the literature comes from the United States, whose cultural foundations are far removed from European cultures and even more from African cultures. These cultural foundations deeply influence the way to implement Lean Six Sigma in organizations.

According to Christophe Bourgeois, the decision to adopt a management instrument is influenced by the institutional environment in the sequence: triggers, driving factors discriminating factors ${ }^{10}$.

In such a complex environment, according to Honorine $\mathrm{Ill}^{11}$, new organizational theories and concepts of modern management (Western and Asian) are required for constantly seeking the performance and competitiveness for African businesses, however, the successful deployment of such concepts is widely dependent on the ability of managers and companies' leaders to adapt these concepts to the specific cultural context of Africa. What makes the role of the leaders more important than ever is the fact they are called upon increasingly to expand their areas of expertise through acquiring knowledge on different managerial cultures.

\section{Conclusion : Sustainability is the new frontier of the Lean Six Sigma}

Africa is one of the richest continents in terms of natural resources. This wealth constitutes a significant potential for economic development for the continent. The protection of these resources has become a major challenge for African economies and sustainable development is a major concern for African economic policy makers.

For African companies, the issue of setting up a Lean Six Sigma goes far beyond concerns of efficiency and improved performance to include the need meet sustainability challenges.

Lean Six Sigma and Sustainability meet at two levels: they share the same willingness to master the creation of value and they have a common enemy which is the "waste" of resources.

\footnotetext{
9"The status of lean implementation within south African aircraft maintenance organizations", Sean Murphy, 2011

${ }^{10} \mathrm{PhD}$ thesis « Entreprise et Instrument de management : facteurs d'adoption et difficultés d'appropriation », Lille 1, 2007

${ }^{11} \mathrm{PhD}$ thesis «Etude des Styles de Management au Burkina Faso et au Sénégal : à la Recherche des Spécificités dy Système de Management Africain »University Groningen, 2012
} 
From this perspective, Lean Six Sigma becomes a suitable tool that combines sustainability and efficiency objectives.

Beyond an environmental commitment, each company has a real interest and challenge to support a sustainable development. The "Lean \& Green" brings Operational Excellence for Environmental Excellence to better meet the new challenges of contemporary business. Establishing a culture driven by Lean and Green management is a key factor in its successful deployment.

\section{REFERENCES}

[1] Raphaël BEAUJEU, Michael KOLIE, Jean-François SEMPERE, Christine UHDER, Chargés de programme, IRAM, Savoir 05, Avril 2011, Transition démographique et emploi en Afrique subsaharienne

[2] Yves Langevin, Conference held in February 1st, 2008, at the «Institut Supérieur des Sciences Économiques et Commerciales » in Libreville (ISSEC).

[3] Christophe Bourgeois, Lille 1, 2007, PhD thesis « Entreprise et Instrument de management : facteurs d'adoption et difficultés d'appropriation »

[4] Claude ALBAGLI, Georges HENAULT, 1996, « La Création d'Entreprise en Afrique, essai de typologie des entreprises africaines 》

[5] GUIDON Performance Solutions, South African financial institution reduces waste and errors with Lean Six Sigma . ttp://www.guidonps.com/industry-news/south-african-financial-institution-reduces-waste-anderrors-with-lean-sixsigma

[6] «Agence Marocaine de Développement des Investissements », communication of May 7th, 2011 called « INMAA, une usine modèle pour les PME marocaines »

[7] Adama Wade, Les Afriques - No 83 - 9 au 15 juillet 2009 "L'après crise a déjà commencé dans les banques »

[8] Entreprendre.ma, 2012, Lancement de l'Université Lean 6 Sigma au Maroc, Jeudi 24 mai 2012. http://www.entreprendre.ma/Lancement-de-I-Universite-Lean-6-Sigma-au-Maroc-Jeudi-24-mai-2012_a5663.html

[9] Xavier Amoros, 2102, "La durabilité est la nouvelle frontière du Lean 6 Sigma », « les Ecos.fr » http://lecercle.lesechos.fr/entreprises-marches/management/leanmanagement/221144556/durabilite-est-nouvellefrontiere-lean-6-si

\section{Author' biography}

\section{Said ELMEZOUARI}

PhD, operational research professor at "National School of Commerce and Management - ENCG"

\section{Zahira BOUAOUDA}

Public Chartered Accountant, PhD Student in sciences of management

\section{Hicham DRISSI}

PhD Student in sciences of management 